\title{
Determination of Trihalomethanes in Drinking Water from Beijing, People's Republic of China
}

\author{
R. S. Zhao, X. T. Wang, A. X. Wei, X. B. Xu
}

Key Laboratory of Environmental Chemistry and Ecotoxicology, Research Center for Eco-Environmental Sciences, Chinese Academy of Sciences, Post Office Box 2871, Beijing 100085, People's Republic of China

Received: 5 January 2004/Accepted: 20 April 2004

In many drinking water treatment plants, chlorination process is still one of the main techniques used for the disinfection of natural water (Cho et al., 2003). Chlorine has traditionally been a preferred disinfection agent because of its proven effectiveness and its being relatively inexpensive (Rodriguez, et al., 2001). The research undertaken in the middle of the 1970s (Rook,1974; Bellar et al.1974), however, indicated this chemical treatment resulted in the formation of trihalomethanes (THMs). The formation of THMs in drinking water results from the reaction of chlorine with naturally occurring organic matters, principally humic acid and fulvic acid (Cho et al., 2003). The THMs formed are mainly composed of chloroform $\left(\mathrm{CHCl}_{3}\right)$, dichlorobromomethane $\left(\mathrm{CHCl}_{2} \mathrm{Br}\right)$, chlorodibromomethane $(\mathrm{CHClBr} 2)$ and bromoform $(\mathrm{CHBr} 3)$. These compounds have drawn significant scientific attention during the last decades, due to the adverse health effects they may have on human beings (Table 1) (Nikolaou et al., 2002). Basing on the potential carinogenicity effects of these compounds, many countries have set limits for THMs in drinking water. In 1979, the United States EPA initiated a regulatory standard of $100 \mu \mathrm{g} \mathrm{l}^{-1}$ for THMs, under the "Safe Drinking Water Act". Currently, this standard has been reduced to $80 \mathrm{\mu g} \mathrm{l}^{-1}$. Reduction of this level to $40 \mathrm{\mu g} \mathrm{l}^{-1}$ is being considered (Nikolaou et al., 2002). In China, the standard of drinking water for chloroform is $60 \mathrm{ug} \mathrm{l}^{-1}$. The World Health Organization (WHO) has also set quality target levels for the concentrations of THMs (Table 1) (Nikolaou et al., 2002). As drinking water is directly linked with people's health, it is important to investigate the levels of THMs and TTHMs in it.

In terms of the analysis of THMs in water, the conventional pretreatment method often needs large amount of toxic solvent and time-consuming procedures. Recently, liquid-phase microextraction (LPME) or solvent microextraction (SME) was developed as a solvent-minimized pretreatment technique (Jeannot et al., 1996), which is fast, simple and inexpensive. This novel technique eliminates the disadvantages of conventional extraction methods, such as time-consuming operation and using specialized apparatus. Since very little solvent is used, there is minimal exposure to toxic organic solvent for the operator. To our knowledge, in routine analysis there is seldom report on the monitoring of THMs in water 
Table 1. Cancer group classification and quality target levels set by the WHO for THMs

\begin{tabular}{lcc}
\hline Compound & Cancer group (EPA) & WHO guideline $\left(\mu \mathrm{gl}^{-1}\right)$ \\
\hline $\mathrm{CHCl}_{3}$ & $\mathrm{~B} 2$ & 200 \\
$\mathrm{CHCl} 2 \mathrm{Br}$ & $\mathrm{B} 2$ & 60 \\
$\mathrm{CHClBr} 2$ & $\mathrm{C}$ & 100 \\
$\mathrm{CHBr} 3$ & $\mathrm{~B} 2$ & 100 \\
\hline
\end{tabular}

${ }^{\mathrm{a}}$ Group B2, probable human carcinogen (sufficient data from animal studies);

Group C, possible human carcinogen.

samples using this new method. In this work, drinking water samples from Beijing City were analyzed by headspace-liquid-phase microextraction

(HS-LPME) combined with a capillary gas chromatography-electron capture detector (GC-ECD).

\section{MATERIALS AND METHODS}

Standard solutions of $100 \mathrm{mgl}^{-1}$ THMs in methanol were purchased from ChemService, Inc. (West Chester. PA, USA), including $\mathrm{CHCl}_{3}, \mathrm{CHCl}_{2} \mathrm{Br}$, $\mathrm{CHClBr} 2$ and $\mathrm{CHBr}$, respectively. HPLC-grade methanol was purchased from Tianjin Siyou Technical Company. 1-octanol and sodium chloride were of analytical grade. 1-octanol were further purified by vacuum distillation for $45 \mathrm{~min}$ to remove residual volatile contaminants, and stored at $4^{\circ} \mathrm{C}$. A fixed concentration of 1,1,1-trichloroethane internal standard $\left(4 \mathrm{mgl}^{-1}\right)$ was prepared in 1-octanol. Working solutions of THMs were diluted using double distilled water, which had been boiled for $1 \mathrm{~h}$ in a large beaker to remove THMs. All solutions were stored at $4^{\circ} \mathrm{C}$ in dark.

Water samples were collected in glass jars $(250 \mathrm{ml})$ with screw caps and Teflon inserts. Glass jars were carefully and completely filled. Samples were stablized by the addition of $25 \mathrm{mg}$ ascorbic acid per $20 \mathrm{ml}$ water samples. The samples were analyzed directly or stored at $4^{\circ} \mathrm{C}$ within $48 \mathrm{~h}$.

A Varian 3740 gas chromatograph equipped with ${ }^{63} \mathrm{Ni}$ electron-capture detection system was used for all analyses. The GC was fitted with a SE-54 capillary column $(40 \mathrm{~m} \times 0.25 \mathrm{~mm}$ I.D. J\& W Scientific Inc.USA). The gas chromatography conditions were as follows: injector temperature $280^{\circ} \mathrm{C}$; detector temperature 300 ${ }^{\circ} \mathrm{C}$; initial oven temperature $50^{\circ} \mathrm{C}$ for $5 \mathrm{~min}$, increased to $275^{\circ} \mathrm{C}$ at a rate of $25^{\circ} \mathrm{C}$ $\min ^{-1}$, then maintained at $275^{\circ} \mathrm{C}$ for $3 \mathrm{~min}$. The total time for one $\mathrm{GC}$ run was $17 \mathrm{~min}$. The inlet was operated in split mode with a split ratio $10: 1$ and nitrogen of high purity was used as carrier gas. A WDL-95 workstation (Dalian Inst. Chem. Phys, CAS, China) was utilized to control the system and for acquisition of analytical data.

THMs in drinking water samples were monitored by capillary gas chromatography with electron capture detector using headspace liquid-phase 
microextraction (HS-LPME) technique. Briefly, a vial with a stir bar was placed on a magnetic stirrer and maintained at a desirable temperature in a water bath. HS-LPME was performed with a commercially available $10 \mathrm{ul} \mathrm{GC}$ microsyringe (Shanghai, China). Before each extraction, the syringe was rinsed for at least 20 times with 1-octanol. During the extraction, the microsyringe was fixed above the extraction vials with a septum. After passing through the septum, the needle tip must be kept about $1 \mathrm{~cm}$ above the surface of sample solution. Then $1 \mu \mathrm{l}$ of the extraction solvent containing I.S. was extruded out of the needle and kept suspending at the needle tip. When the extraction was finished, the drop was retracted into the needle and injected directly into the GC inlet.

\section{RESULTS AND DISCUSSION}

Several factors have been found to affect the sensitivity of the LPME technique for GC-ECD analysis. Among the organic solvents, xylene, ethylene glycol and 1-octanol, 1-octanol was the most suitable solvent for the analytes. Extraction conditions such as headspace volume, extraction time, stirring rate, extraction temperature and salting-out effect were optimized. The optimized conditions were as follows: $15 \mathrm{ml}$ headspace volume in a $40 \mathrm{ml}$ vial, $10 \mathrm{~min}$ extraction time, 800 rpm stirring rate at $20^{\circ} \mathrm{C}$ and $0.3 \mathrm{~g} \mathrm{ml}^{-1} \mathrm{NaCl}$ added. These conditions must be kept constant during the procedure of analysis.

Extended standard method was used for quantitative determination of the THMs. Five point calibration curves with concentrations of $1,10,30,50,100 \mu \mathrm{g} \mathrm{l}^{-1}$ for four THMs, were used, which give high correlation coefficients $(\mathrm{R})$ than 0.995 . The recoveries for $\mathrm{CHCl}_{3}, \mathrm{CHCl}_{2} \mathrm{Br}, \mathrm{CHClBr} 2$ and $\mathrm{CHBr} 3$ were from 101 to $112 \%$ in tap water and well water. The repeatability of the method was determined by performing six times using aqueous standard solutions with $10 \mu \mathrm{g}$ $\mathrm{I}^{-1}$ THMs. The RSD $\%$ was found to be below $10 \%$ except that the repeatability of $\mathrm{CHCl}_{3}$ was $11.3 \%$. The limits of detection (LODs), based on a signal-to-noise ratio $(\mathrm{S} / \mathrm{N})$ of 3 , ranged from $0.15\left(\mathrm{CHCl}_{2} \mathrm{Br}\right.$ and $\left.\mathrm{CHClBr} 2\right)$ to $0.4 \mu \mathrm{g} \mathrm{l}^{-1}\left(\mathrm{CHCl}_{3}\right)$, which were sensitive enough to determine THMs at the required levels in the present study.

The sampling sites cover 4 main tap water factories in Beijing City. They are located in the west (S1), south (S2), east (S3) and north (S4) of the city, respectively, and are providing $80 \%$ drinking water of the whole city $(2,400,000 \mathrm{t}$ per day). Raw water of S4 comes from Miyun Reservoir while that of S1 and S3 is groundwater, and raw water of S2 constitutes $50 \%$ each of water from Miyun Reservoir and groundwater. Fig.1a shows the concentrations of THMs in raw water of four tap water factories. In view of THMs, raw water of four tap water factories has only small differences. It is obvious that raw waters of S3 and S4 are less contaminated by THMs. Although chloroform level $\left(3.12 \mu \mathrm{g}^{-1}\right)$ in S2 is extremely high when compared with that in the other three raw waters, it is close to the data reported $\left(3.0 \mu \mathrm{g} \mathrm{l}^{-1}\right)$ by huang et al in 1987 (Huang et al., 1987) and much lower than the maximum value previously reported $\left(12 \mathrm{Hg} \mathrm{l}^{-1}\right)$ by ( Zhao 


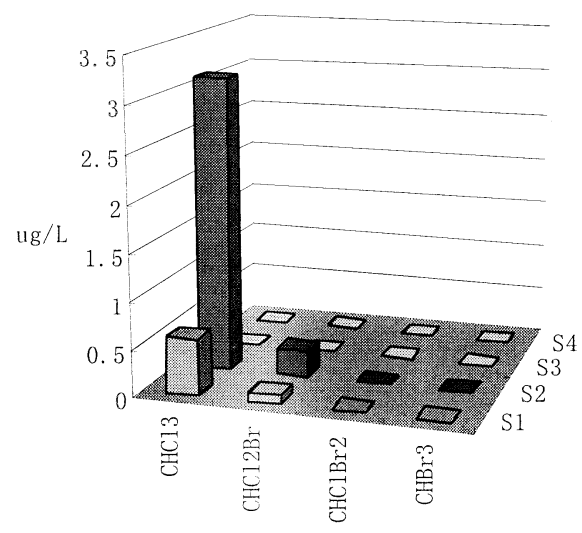

a

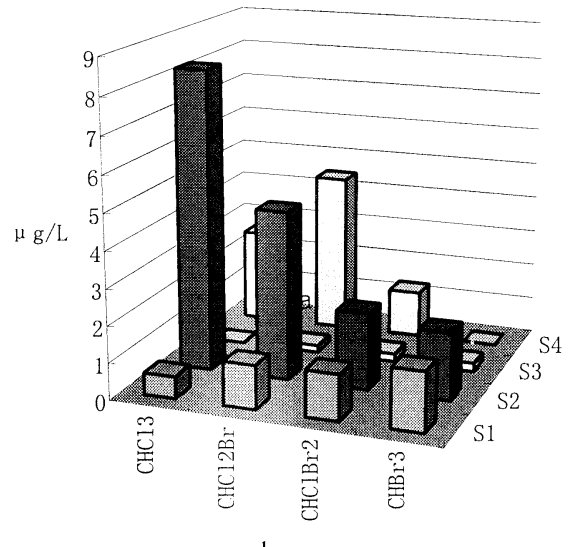

b

Figure 1. Concentrations of THMs in water samples
a. Raw water samples
b. Tap water samples

et al., 1986). It was reported that in raw water of Jialingjiang tap water factory of Chongqing chloroform level ranged from 3.0 to $4.2 \mu \mathrm{g} \mathrm{l}{ }^{-1}$ (Huang et al., 1987 ).

Fig.1b shows the concentrations of THMs in tap water of four tap water factories. For all samples, concentrations varied, between 0 and $8.26 \mathrm{\mu gl}^{-1}$ (chloroform ), 0.185 and $4.63 \mathrm{\mu g} \mathrm{l}^{-1}$ (dichlorobromomethane), 0.218 and $2.09 \mathrm{\mu g} \mathrm{l}^{-1}$ (chlorodibromomethane), 0 and $1.83 \mathrm{\mu g} \mathrm{l}^{-1}$ (bromoform), with the mean concentrations of $2.86,2.61,1.21$, and $0.91 \mathrm{ug} \mathrm{l}^{-1}$, respectively. THMs levels in S2 and S4, whose raw waters are surface water of Miyun Reservoir, are higher than those of S1 and S3, whose raw waters are groundwater. It is clear that the concentrations of THMs in tap water have close relationship with the raw water. Previous investigations also drawn the same conclusion (Zhao et al., 1986). It means that surface water of Miyun Reservoir contains much more organic matrices, which can react with available chlorine in the disinfection, than groundwater. 
Table 2. Comparison of THMs and TTHMs levels $\left(\mu \mathrm{g} 1^{-1}\right)$ in tap water from other areas and Beijing

\begin{tabular}{|c|c|c|c|c|c|c|c|}
\hline Locality & $\begin{array}{c}\text { Survey } \\
\text { year }\end{array}$ & $\mathrm{CHCl} 3$ & $\mathrm{CHCl} 2 \mathrm{Br}$ & $\mathrm{CHClBr} 2$ & $\mathrm{CHBr} 3$ & TTHMs & Reference \\
\hline $\begin{array}{c}\text { Zhabei District } \\
\text { of Shanghai }\end{array}$ & \multirow{8}{*}{1997} & 14.65 & 22.66 & 20.08 & 8.43 & 65.82 & \multirow{8}{*}{$\begin{array}{l}\text { Yan JC } \\
(2002)\end{array}$} \\
\hline $\begin{array}{l}\text { Tanggu District } \\
\text { of Tianjin }\end{array}$ & & 33.66 & 20.63 & 8.05 & 0.61 & 62.95 & \\
\hline $\begin{array}{c}\text { Chengguan District } \\
\text { of Lanzhou }\end{array}$ & & 10.65 & 3.62 & 0.91 & & 15.18 & \\
\hline $\begin{array}{c}\text { Chaoyang District } \\
\text { of Beijing }\end{array}$ & & 9.95 & 4.31 & 1.18 & & 15.44 & \\
\hline $\begin{array}{l}\text { Haidian District } \\
\text { of Beijing }\end{array}$ & & 0.49 & & & & 0.49 & \\
\hline $\begin{array}{l}\text { Fengtai District } \\
\text { of Beijing }\end{array}$ & & 0.67 & & 1.63 & 11.83 & 14.13 & \\
\hline $\begin{array}{l}\text { Xicheng District } \\
\text { of Beijing }\end{array}$ & & 8.98 & 3.58 & 1.80 & 1.72 & 16.08 & \\
\hline $\begin{array}{c}\text { Xuanwu District } \\
\text { of Beijing }\end{array}$ & & 2.39 & 0.78 & 1.67 & 2.92 & 7.76 & \\
\hline Alacant of Spain & \multirow{4}{*}{$\begin{array}{c}2001 \\
\text { or } \\
\text { earlier }\end{array}$} & 13.6 & 24.73 & 25.67 & 21.93 & 85.93 & Villanueva \\
\hline Barcelona of Spain & & 20.00 & 22.68 & 10.81 & 10.19 & 63.64 & $\mathrm{CM}$ \\
\hline Asturias of Spain & & 14.57 & 4.96 & 2.23 & 0.56 & 22.25 & et al. \\
\hline Tenerife of Spain & & 0.39 & 0.85 & 1.18 & 5.55 & 8.00 & $(2003)$ \\
\hline Beijing City & 2003 & 2.86 & 2.61 & 1.21 & 0.91 & 7.59 & $\begin{array}{c}\text { Present } \\
\text { work }\end{array}$ \\
\hline
\end{tabular}

To understand the status of THMs contamination in the tap water of the city, the levels of THMs and TTHMs determined in the present study were compared with the results in tap water obtained from different places and Beijing in 1997 (Table 2) (Yan, 2002). Among the data the concentration levels of THMs and TTHMs in Beijing in 1997 were close to or higher than those of the recent data, while our data were lower than those of Zhabei District of Shanghai, Tanggu District of Tianjin, and close to those of Chengguan District of Lanzhou. Then we can conclude that the present contamination levels of THMs in Beijing City are lower than those in other areas of China. At the same time, total and specific THM levels in the present work are close to or lower than results reported in four provinces of Spain (Villanueva et al, 2003). Our preliminary survey showed that the concentrations of THMs and TTHMs in tap water of Beijing City were much lower than the recommended maximum residue levels in drinking water established by the guideline of the World Health Organization (WHO) (Table 1).

Acknowledgment. This work was jointly supported by the Chinese Academy of Sciences and State Science and Technology Council Program. 


\section{REFERENCES}

Bellar TA, Lichtenberg JJ, Kroner RC (1974) The occurance of organohalicles in chlorinated drinking water. J American Water Works Assoc 66: 703-706

Cho DH, Kong SH, Oh SG (2003) Analysis of trihalomethanes in drinking water using headspace-SPME technique with gas chromatography. Water Res 37: 402-408

Huang J, Fan Q, Kou G, Liu C (1987) Survey of haloforms in the main drinking water plants of our country. China Environ Chem 6: 80-86

Jeannot MA, Cantwell FF(1996) Solvent microextraction into a single step.Anal Chem 68: 2236-2240

Nikolaou AD, Lekkas TD, Golfinopoulos SK, Kostopoulou MN (2002) Application of different analytical methods for determination of volatile chlorination by-products in drinking water. Talanta 56: 717-726

Rodriguez MJ, Serodes JB (2001) Spatial and temporal evaluation of trihalomethanes in three water distribution systems. Water Res 35: $1572-1586$

Rook JJ (1974) Formation of haloforms during chlorination of natural water. Water Treat Exam 23: 234-243

Villanueva CM, Kogevinas M, Grimalt J O (2003) Haloacetic acids and trihalomethanes in finished drinking waters from heterogeneous sources. Water Res 37: 953-958

Yan JC (2002) Environmental analysis. Chemical Industry Press, Beijing, p141

Zhao GD (1986) A preliminary investigation of volatile halogenated Hydrocarbons in drinking water of some provinces and cities in our country. China Environ Chem 3: 84-86 